\title{
HISTÓRIAS ESQUECIDAS DO ESPORTE
}

Leonardo Brandão

\section{Resumo}

Considerado atualmente como um dos esportes radicais que mais mobiliza jovens ao redor do mundo, especialmente nos Estados Unidos e no Brasil, o skate nem sempre teve seu processo de esportivização voltado para o "culto" das manobras radicais ou para a formação de contraculturas urbanas. Este artigo, fruto de algumas pesquisas realizadas para uma tese de doutoramento em História, busca evidenciar tanto um passado pouco conhecido do skate - ligado ao brincar e ao surgimento e desenvolvimento do patim quanto problematizar esses silenciamentos em nome de uma articulação, pelo viés mercadológico, entre esporte e contracultura.

\section{Palavras-Chave}

Patim; Skate; Brincadeiras; Esportes, Contracultura.

\section{FORGOTTEN HISTORIES OF THE SPORT}

Leonardo Brandão

\begin{abstract}
Considered today as one of the sports that attracts more young people around the world, especially in the United States and Brazil, the skating was not always the process of esportivization toward the "cult" of radical maneuvers or the formation of counter urban. This article, the result of some researches for a doctorate in history, both find evidence of a past unknown skate - on the play and the emergence and development of skating - the question silently in the behalf of a joint, by marketing bias, between sports and counterculture.
\end{abstract}

\section{Key-Words}

Skating; Skateboarding; Games; Sports; Counterculture. 


\section{DO BRINCAR AO PATINAR: uma breve introdução}

"Só os pensamentos que surgem em movimento têm valor" Friedrich Nietzsche

Sob diversos aspectos, as atividades físicas - muitas delas hoje esportivizadas - desenvolveram-se a partir de brincadeiras arcaicas praticadas por diferentes sociedades históricas. No entanto, a formação daquilo que Pierre Bourdie (1983) chamou de "campo esportivo"- um complexo mercado de interesses formado por técnicos, médicos, jornalistas, juízes, campeonatos, jogadores e/ou praticantes profissionais, associações, empresas, fábricas, clubes, federações etc - turva, na maioria dos casos, a associação outrora evidente entre o lúdico e a atividade física. Embora muitos dos exercícios físicos pré-existentes aos esportes modernos tenham recebido um significado e uma função radicalmente novos, é possível afirmar que eles se desenvolveram de um mesmo pressuposto fundamental: a brincadeira.

De acordo com o historiador neerlandês Johan Huizinga - que publicou no ano de 1938 a primeira edição de seu "Homo Ludens", obra de grande repercussão e importância por colocar o jogo, a brincadeira e o lúdico como elementos centrais e essências para o desenvolvimento da vida e da cultura - faz-se importante evidenciar o papel do "brincar" como uma forma específica de atividade, com funções sociais e estéticas relevantes. Também por volta dessa época da publicação do "Homo Ludens”, o filósofo Walter Benjamin, um dos mais notáveis intelectuais alemães do século XX, colocava que a "brincadeira, e nada mais, era o que estava na origem de todos os hábitos" (BENJAMIN, 1994, p. 253). Assim, se a brincadeira, o jogo e o lúdico possuem uma história, e uma história que remete, como coloca Huizinga, às "principais bases da civilização" (HUIZINGA, 1996, p. 08), não se deve estranhar tais elementos numa tese que trata, fundamentalmente, de um processo de esportivização.

Que outra coisa possibilitaria o surgimento do skate que não estivesse ligado ao ato de brincar, ao lúdico e ao divertimento? Mesmo sua posterior capitalização e produção em série não seriam possíveis sem que este universo dos lazeres não estivesse, desde sempre, presos a sua concepção inicial, que é o ato de equilibrar-se em velocidade, brincar com o corpo em vertigem.

De brinquedo de menino a profissão, de rebeldia juvenil a esporte espetáculo, a história do skate faz parte da história do brincar a partir de diversos tipos de deslizamentos. Segundo algumas fontes, arqueólogos demonstraram ser muito antigo o desejo do homem por encontrar formas diferenciadas de andar que não 
estejam, exclusivamente, presas aos passos cadenciados das pernas. Para romper o ciclo vicioso do andar e inventar formas de locomoção mais rápidas, úteis ou diferentes, antigos habitantes da região onde hoje se localiza a Noruega, por volta do ano 1000 a.C. deram forma a um tipo muito peculiar de deslizamento: a patinagem (do inglês, skating). Habitantes de lugares frios, eles passaram a acoplar sob suas pernas alguma espécie de patins feitos de ossos maxilares de veados ou de outros animais que possuíam mandíbulas compatíveis ao formato de seus pés ${ }^{1}$.

Não há, evidentemente, uma linha do tempo que liga essa prática aos modernos patins e skates contemporâneos; percorrê-la seria cometer o mesmo erro de quem assegura ser o futebol um jogo - em formato civilizado - das antigas tribos que chutavam crânios humanos, como explica o pesquisador Ademir Gebara (2002, p.17). As funções e os motivos para o “deslizar” eram seguramente diferentes, mas é possível afirmar que tanto a antiga patinagem quanto a patinagem moderna não seriam possíveis sem um elemento lúdico e corporal que as definem, ou seja, o equilíbrio do corpo em velocidade. Em outras palavras, mesmo que seja para ir atrás da caça, é possível imaginar os antigos "noruegueses" rindo e brincando ao tentarem se equilibrar em seus patins com ossos e, eventualmente, levando alguns tombos.

Embora a patinagem no gelo seja bastante antiga - sendo que na Idade Média os ossos foram substituídos por elementos que passaram a causar um menor atrito com o gelo, como lâminas de madeira e posteriormente, lâminas de ferro, sendo a patinação usada primeiro para atravessar lagos congelados e, mais tarde, como forma de recreação ${ }^{2}$ - foi somente no século XVIII que apareceram as primeiras espécies de patins com rodas, e como demonstra a figura a seguir, essas rodas eram acopladas aos calçados de seus praticantes.

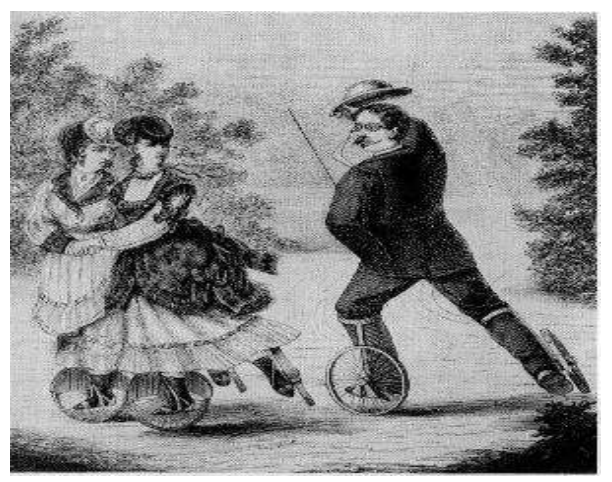

FIGURA 1: Gravura retratando a patinagem na Europa no século XVIII. Fonte: Disponível em: http://cnriomaior.tripod.com/historia.html

\footnotetext{
${ }^{1}$ Disponível em: http://www.janna.com.au/Skate/history.htm. Acesso em: 23 maio 2009.

${ }^{2}$ Disponível em: http://www.centroeducacional.ufla.br/educacaofisica/paneparapan2007projeto.doc. Acesso em: 24 maio 2009. Conexões: revista da Faculdade de Educação Física da UNICAMP, Campinas, v. 7, n. 2, p. 13-23, maio/ago. 2009. ISSN: 1983-930.
} 
Registrou-se o nome do holandês Hans Brinker como o primeiro fabricante de rodas metálicas em patins no ano de 1733, e o nome de Joseph Merlin, um fabricante de instrumentos musicais nascido em Huys, na Bélgica, como um dos primeiros divulgadores dessa prática na Europa ${ }^{3}$. Não deixa de ser cômico, todavia, o episódio que inaugurou a exibição, feita em Londres, dos primeiros patins com rodas que o próprio Merlin fabricou em sua oficina. Segundo um jornal de notícias londrino do ano de 1770

\begin{abstract}
Uma das suas inovações engenhosas foi um par de patins concebido para correr, com umas pequenas rodas metálicas. Provido com um par de patins e um violino, Merlin decidiu causar sensação num baile de máscaras em Soho Square, Londres. Sem saber como retardar a velocidade a que ia, e sem saber como mudar a direção, colidiu com um espelho de valor superior a 500 libras. Tanto o espelho quanto o seu violino ficaram em pedaços e Merlin ficou gravemente ferido" ${ }^{4}$
\end{abstract}

Interessante notar nessa citação - que pode ser vista entre os mitos fundadores do patinar - que desde sempre esta prática esteve relacionada ao perigo de cair e, consequentemente, de se machucar. Talvez resida justamente neste brincar com o corpo em velocidade a chave para se entender, paradoxalmente, o prazer que ela suscita quando nada dá errado e nenhuma queda se anuncia. De toda forma, nos anos posteriores, novas invenções foram aprimorando os patins de Merlin, como os patins de quatro rodas patenteado pelo inglês James Leonard Plimpton no ano de 1870, os quais buscavam proteger um pouco mais o patinador por possuir um "tacão" de borracha na parte da frente, usado para "frear" no caso do praticante atingir uma velocidade excessiva.

Durante a Belle Époque, com a prática da patinação em rinques e parques existentes em vários países da Europa e na América do Norte - a patinação chega ao Brasil no início de 1900 - ela se torna um pretexto para o encontro da elite, a qual acabou por desenvolver a partir dessa prática um novo esporte, chamado de patinação artística, onde o patinador (homens e mulheres, individualmente ou em dupla) passava a se apresentar para o público presente e tinha a sua performance avaliada por juízes qualificados em avaliar a graça, plasticidade e a leveza nos movimentos.

Foi dessa brincadeira de deslizar sobre rodas que surgiu o skate, sendo sua história relacionada diretamente ao patim. De acordo com o pesquisador Rhyn Noll (NOLL, 2000), foi retirando os eixos e as rodas dos patins e os acoplando a uma pequena tábua que, no ano de 1918, um garoto norte-americano chamado Doc Ball, construiu, brincando, o primeiro modelo daquilo que viria a ser chamado de skateboard, ou o "patim de tábua", o qual acabou sendo patenteado no ano de 1939.

\footnotetext{
${ }^{3}$ Disponível em: http://cnriomaior.tripod.com/historia.html. Acesso em: 23 maio 2009. ${ }^{4}$ Id. Conexões: revista da Faculdade de Educação Física da UNICAMP, Campinas, v. 7, n. 2, p. 13-23, maio/ago. 2009. ISSN: 1983-930.
} 
Associado primeiramente ao lúdico e às brincadeiras de deslizamento, tanto o skate quanto o patim tornarse-iam também esportes bastante populares nos Estados Unidos e em demais países da Europa e América Latina ao longo do século XX. Historicamente, a primeira tendência que se observa acerca da esportivização do skate data de meados da década de 1950, seguindo o skate o mesmo modelo do que vinha sendo realizado com o patim artístico. Em reportagens veiculadas no Brasil pela revista Manchete durante a década de 1970, por exemplo, é possível compreender a similitude do patim artístico com o skate de competição. Numa matéria de Maria Costa Pinto que narra um campeonato ocorrido em Long Island/EUA neste período, é colocado que "os campeões de skate demonstraram que têm o equilíbrio elegante dos bailarinos, a força dos acrobatas e a precisão de um grande esquiador que desliza por entre obstáculos sem derrubá-los" ${ }^{\prime 5}$ De acordo com a reportagem,

Ao som de música pop, 35 craques - o mais novo com 8 anos e o mais velho com 26 - participaram de uma exibição/competição organizada pela recém-fundada National Skateboard Shows, que gastou 250 mil dólares no recente espetáculo de dois dias no Nassau Coliseum, em Long Island. O objetivo, segundo o presidente do Skateboard, é "provar que o skate não é mais uma moda, mas um novo e sério esporte de competição". (Manchete, n. 1263, p. 141, 1976).

O uso do skate para competições e exibições esportivas começou a dar uma maior visibilidade para esta atividade ao tentar transformá-la de brincadeira ou "moda" em algo "sério" e competitivo. Outro ponto interessante de ser notado é que o skate, nesta época, era muito praticado por mulheres dado a associação, hoje desfeita, entre skate e patinação artística. Na figura seguinte, é possível observar uma garota realizando um movimento sobre o skate que lembra muito um passo de balé contemporâneo.

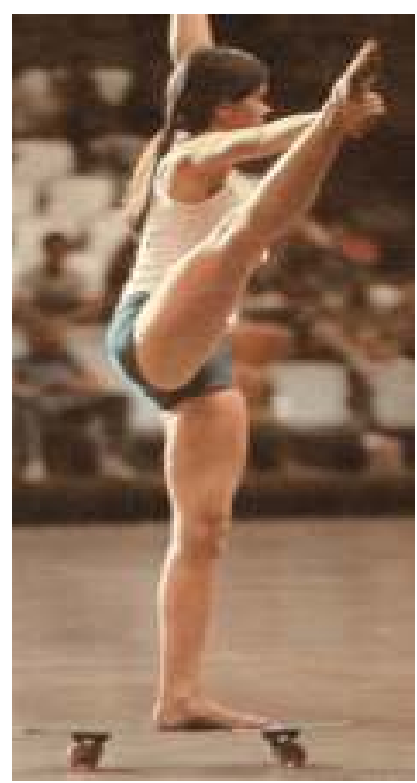

FIGURA 2: Skatista com movimentos similares ao balé e a patinação artística.

Fonte: Manchete, n. 1263, 03 jul. 1976.

${ }^{5}$ Manchete, n. 1263, p. 140, 03 jul. 1976.

Conexões: revista da Faculdade de Educação Física da UNICAMP, Campinas, v. 7, n. 2, p. 13-23, maio/ago. 2009. 
Além da ausência de calçados, a roupa utilizada pela skatista em nada lembra as roupas geralmente usadas pelas skatistas nos tempos atuais, como bonés ou calças jeans. Tratava-se, esteticamente, de algo muito diferente da feição que esta prática ganharia tempos depois. Como o skate era associado ao patim, essa questão do gênero era menos flagrante do que a caracterização tomada a partir da década de 1980, quando o skate passou a representar mais o universo masculino e o patim o universo feminino. Nas décadas de 1960 e 1970, nos Estados Unidos, mulheres como Laura Thornhill, Kim Cespedes, Wendy Bearer, Ellen O'Neal, Terri Brown, Leilani Kiyabu, entre outras, faziam uso do skate profissional tanto em campeonatos quanto em demonstrações. A porta aberta para o profissionalismo no skate feminino, entretanto, deu-se por intermédio de Patti McGee, a primeira norte-americana a se tornar profissional neste esporte no ano de 1965. Por este feito, a skatista foi capa da revista norte-americana Life neste mesmo ano. A Life, por ser uma das revistas de maior circulação na época, ajuda a pensar a expressividade que o skate estava ganhando na sociedade estadunidense nos anos 60. Em nada a imagem lembra o viés da contracultura que o skate tomaria anos mais tarde, era tão somente uma ginástica de equilíbrio e precisão. Tratava-se de um novo esporte surgido de uma ramificação do patim e sem conotações transgressivas.

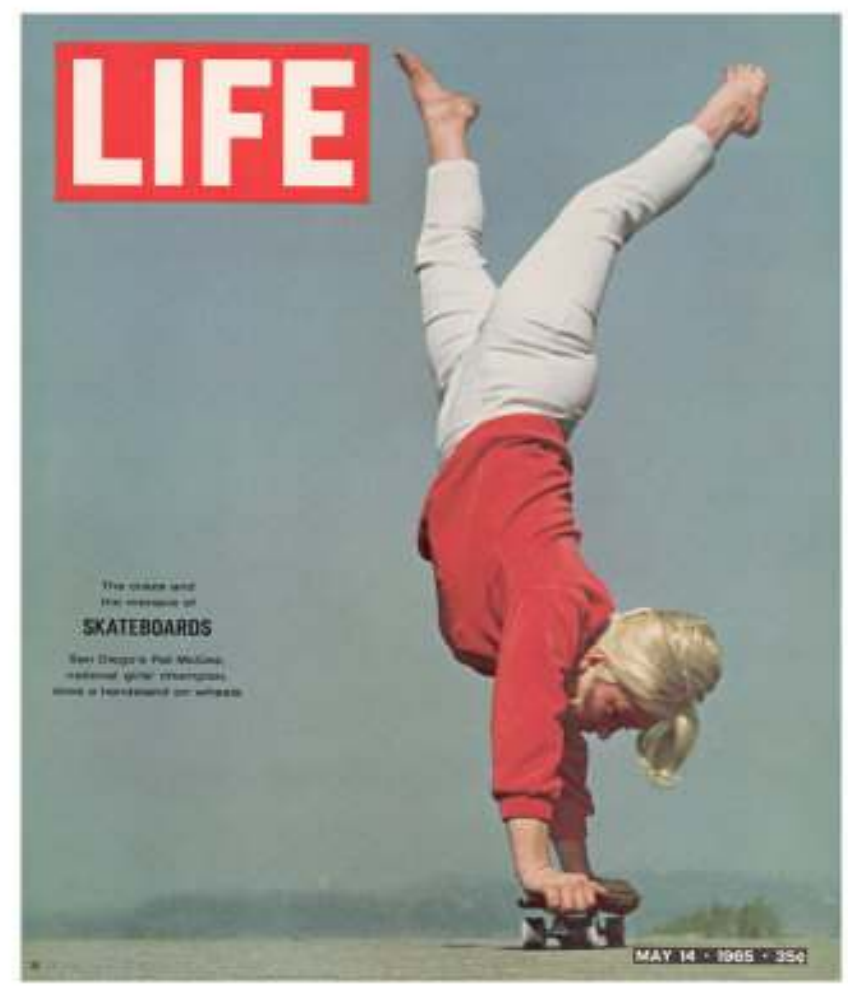

FIGURA 3: Life Magazine, may 1965. 
$\overline{\text { No Brasil, o skate, que foi introduzido em meados da década de 1960, também apresentou uma tendência de }}$ esportivização com base nos movimentos inspirados na patinação artística. De acordo com o skatista carioca Guto Jimenez, "naquela época as manobras eram basicamente reproduções de movimentos de patinação artística, de ginástica rítmica ou bale" ${ }^{\circ}$. Tal característica do skate pode ser observada através de uma matéria veiculada pelo "Fantástico", programa televisivo exibido pela Rede Globo que, em meados da década de 1970, apresentou a equipe brasileira que viajou para os Estados Unidos para participar de um Campeonato Mundial de Skate. Através da emblemática narração de Cid Moreira, o programa divulgava que eles faziam "todo tipo de evolução, salto em altura e rodopios impressionantes", demonstrando que a equipe contava com um técnico, o treinador Eduardo de Souza Júnior, equipamentos de proteção e uniformes padronizados com o patrocínio da Pepsi.

Caminhando por este viés da profissionalização, o skate se tornou, com o avançar da década de 1970, um grande fenômeno social e mercadológico. Nos Estados Unidos, por exemplo, segundo um livro escrito no ano de 1978 pelos pesquisadores Alain Morel e Gilles Ouaki, as estatísticas do período demonstram tanto um rápido crescimento no número de praticantes, "8 milhões de skatistas em 1974; 14 milhões em 1975; 21 milhões no ano seguinte; mais de 40 milhões em 1978" quanto no mercado de negócios, "em 1976, nos EUA, foram vendidos nada menos do que 5 milhões de skates" (MOREL; OUAKI, 1978, p. 14).

Se fosse óbvio o curso da história, o skate seria hoje uma atividade muito próxima à patinação artística, que desde 1977 é reconhecida pelo Comitê Olímpico Internacional (COI) e presente nos jogos pan-americanos e demais competições esportivas de caráter transnacional. No entanto, em função do contexto histórico do período - e pela influência do surf na prática do skate - grandes modificações passaram a ocorrer nos rumos dessa profissionalização; desviando seu processo até então verificável de esportivização e normatização institucional. Com a influência do surf e ascensão da juventude representada como um ator social e "rebelde", o skate passou a se desvincular da patinação artística e ser usado como símbolo de uma nova geração de esportistas que buscava, ao invés de seguir qualquer tradição, inventar o novo, o inusitado ou, em outras palavras, transgredir às próprias vivências do esporte. Conceitualmente, é possível dizer que o skate foi se retirando do "american way of life" e se inserindo, cada vez mais, na contracultura juvenil.

\footnotetext{
${ }^{6}$ Disponível em: http://skateboardingmilitant.blogspot.com/. Acesso em: 24 maio 2009.

${ }^{7}$ Disponível em: http://especiais.fantastico.globo.com/fantastico30anosatras/?s=skate. Acesso em: 20 maio 2009.

Conexões: revista da Faculdade de Educação Física da UNICAMP, Campinas, v. 7, n. 2, p. 13-23, maio/ago. 2009.

ISSN: 1983-930.
} 


\section{SKATE E CONTRACULTURA}

A escassez de referências a este passado do skate situado entre as décadas de 1950 e 1970, quando sua esportivização seguia o rumo e o exemplo do que era feito na patinação artística, leva ao questionamento sobre o porquê desses silenciamentos ou omissões. O passado, como se sabe, possui vozes e vozes que precisam ser ouvidas antes que sejam soterradas. No entanto, grande parte desse passado "renegado" do skate ocorreu em função de sua esportivização, que a partir de meados da década de 1970 passou a sofrer influências da contracultura jovem. Paradoxalmente, essa associação apresentou-se como um melhor investimento mercadológico do que o balé artístico e a patinação. Dentro da lógica de um mercado que passava a girar cada vez mais dependente de uma juventude transviada, a associação entre o skate e a contracultura tornou-se um nicho promissor e muito lucrativo.

Historicamente, as décadas de 1960 e 1970 comportam diversos segmentos da juventude que passaram a buscar, como explica Francisco Assumpção Júnior (2004), quebrar tabus, diferenciar-se socialmente e invocar liberdades não imaginadas anteriormente. Segundo este autor, é nesta época que se inicia "o culto ao corpo, com seios soltos sob blusas, regimes de emagrecimento e exercícios de musculação" ${ }^{8}$. Desta forma, como demonstram algumas imagens sobre skate observadas nos anos finais da década de 1970 e, sobretudo, durante a década de 1980: o visual alternativo - cores fortes, calças jeans rasgadas, cabelos desgrenhados que os praticantes de skate passaram a adotar já não lembra os tons pastéis, os uniformes e a harmonia dos movimentos da patinação artística. De acordo com um depoimento do skatista Fábio Bolota, o punk (um dos movimentos da contracultura) em muito influenciou a prática do skate.

O que fez o skate se tornar popular de verdade foi a roupagem do punk-rock que se incrustava nos praticantes de todo o mundo. Quem virou a mesa de fato, ninguém arrisca dizer, mas a mesa foi totalmente virada. Calça descolorida e rasgada, com a camiseta da banda preferida e um bracelete de pontas. Skate or Die! Skate and Destroy! Go Skate or Go Home, ou qualquer frase de efeito estavam ecoando em cada quarteirão. Marcando muito bem essa atitude, o $2^{\circ}$ Campeonato Brasileiro de Guaratinguetá foi um desfile de punks e simpatizantes. A cidade foi invadida por alfinetes e penteados que iam do moicano ao espigado ou pintado. Essa atitude começou a incomodar os moradores da pacata cidade, e logo após eles entraram em guerra contra os skatistas ${ }^{9}$.

Num livro publicado originalmente em 1968, Theodore Roszak observou que a contracultura constituía a matriz de um futuro alternativo e no qual a juventude estaria refazendo, pela negação, a cultura de seus antecedentes. No entanto, o fato do autor escrever imerso no momento da ebulição desse movimento revela sua esperança nos jovens e o medo de que as manifestações destes fossem incorporadas pelo sistema capitalista. Em 1968, Roszak temia que esse movimento juvenil viesse a se reduzir a um conjunto pitoresco

\footnotetext{
${ }^{8}$ Id., p. 10 .

${ }^{9}$ BOLOTA, F. Anos 80. In: BRITTO, E. (Org.). A onda é dura: 3 décadas de skate no Brasil. São Paulo: Parada Inglesa, 2000. p. 33.

Conexões: revista da Faculdade de Educação Física da UNICAMP, Campinas, v. 7, n. 2, p. 13-23, maio/ago. 2009.

ISSN: 1983-930.
} 
de símbolos, gestos, maneiras de vestir e slogans; o que faria da contracultura apenas algo temporário, sem meios para realizar uma verdadeira mudança social e cultural.

De fato, muitos dos temores de Roszak se concretizaram. Mesmo as décadas de 1960 e 1970, tidas como o auge da contracultura, constituíam uma época fortemente comercial. Segundo Nicolau Sevcenko (2001), os novos modos de vida instaurados com a contracultura circulavam pelas esferas do capitalismo e pelas técnicas da publicidade. De acordo com esse autor, a revolução cultural dos anos de 1960 e 1970, marcados por gestos de indignação, idealismos e pela estética do corpo jovem, teve um forte apelo mercadológico, o que possibilitou o preenchimento do imaginário jovem com artigos de consumo que, através de técnicas sutis de controle do desejo, apresentavam-se como um charme pretensamente "irreverente" e "desreprimido".

Se por um lado, a associação entre skate e contracultura ajudou no aumento no número de praticantes e acalentou as vendas de equipamentos destinados a esta atividade, ela também contribui para a formação de um imaginário social acerca deste esporte. Em 2007, por exemplo, o Jornal Estado de Minas Gerais noticiou um evento envolvendo policiais e skatistas: uma câmera de vídeo de segurança urbana filmou jovens skatistas sendo agredidos por policiais no centro de Belo Horizonte. Este episódio entrou no ar pela TV Alterosa (filiada da SBT) e acabou na Câmara Municipal e na Assembléia Legislativa da cidade ${ }^{10}$. Mais recentemente, no ano de 2008, um jovem foi proibido de entrar num shopping center na cidade de Curitiba/PR porque estava usando "roupas de skatista"".

Ao transitar entre a formação de um "campo esportivo", com campeonatos, juízes, atletas profissionais etc, mas também por ser alvo de estigma e marginalização, é possível atualmente pensar o skate, para utilizar um termo proposto por Zygmunt Bauman (1999), como um objeto ambivalente. De acordo com este autor, considera-se ambivalente todo e qualquer objeto que a ele são possíveis de serem identificadas variações antagônicas de representação social. Neste sentido, a ambivalência é uma noção desenvolvida por Bauman (1999) e criada para analisar a falência do projeto Iluminista de organizar, classificar e separar a ordem do caos.

\footnotetext{
${ }^{10}$ É possível assistir as cenas de agressão contra os skatistas acessando o link: Disponível em: http://uaimidia.com.br/html/webs/Módulos/streaming/getstreaming?fire=200707D0925485984.wmv.

${ }_{11}$ Disponível em: http://www1.folha.uol.com.br/folha/cotidiano/ult95u409566.shtml. Acesso em: 13 jun. 2008.

Conexões: revista da Faculdade de Educação Física da UNICAMP, Campinas, v. 7, n. 2, p. 13-23, maio/ago. 2009.

ISSN: 1983-930.
} 
O skate, embora seja um dos esportes mais praticados no Brasil, com mais de três milhões de adeptos ${ }^{12}$, não é ensinado em escolas por professores de Educação Física ou estudado em cursos de graduação em esportes no país. Segue como uma atividade muito praticada, mas pouco compreendida. Entender melhor o seu passado, no entanto, talvez seja uma forma de projetá-lo de forma diferente no futuro.

\section{REFERÊNCIAS}

BAUMAN, Z. Modernidade e ambivalência. Rio de Janeiro: Zahar, 1999.

BENJAMIN, W. História cultural do brinquedo: brinquedo e brincadeira, observações sobre uma obra monumental. In: BENJAMIN, W. Magia e técnica, arte e política: ensaios sobre literatura e história da cultura. 7. ed. São Paulo: Brasiliense, 1994.

BOLOTA, F. Anos 80. In: RITTO, E. (Org.). A onda é dura: 3 décadas de skate no Brasil. São Paulo: Parada Inglesa, 2000.

BOURDIEU, P. “Como é possível ser esportivo?”. In: BOURDIEU, P. Questões de sociologia. Rio de Janeiro: Marco Zero, 1987, p. 137-153.

GEBARA, A. História do esporte: novas abordagens. In: PRONI, M. W.; LUCENA, R. de F. (Org.). Campinas: Autores Associados, 2002, p. 5-29.

HUIZINGA, J. Homo ludens: o jogo como elemento da cultura. 4. ed. São Paulo: Perspectiva, 1996.

ASSUMPÇÃO JÚNIOR, F. A questão da beleza ao longo do tempo. In: BUSSE, S. R. (Org.). Anorexia, bulimia e obesidade. Barueri: Manole, 2004.

MOREL, A.; OUAKI, G. Todo sobre el skateboard. Barcelona: Caralt, 1978.

NOLL, R. Skateboard retrospective. EUA: Schiffer Book, 2000.

ROSAK, T. A contracultura. 2. ed. Petrópolis: Vozes, 1972.

SEVCENKO, N. A corrida para o século XXI: no loop da montanha-russa. São Paulo: Cia das Letras, 2001.

\footnotetext{
${ }^{12}$ Disponível em: www.folha.uol.com.br/folha/esporte/ult92u102808.shtml. Acesso em: 15 jun. 2006. 


\section{Leonardo Brandão}

\section{Pontifícia Universidade Católica de São Paulo}

\section{Referência do artigo}

ABNT

BRANDÃO, L. Histórias esquecidas do esporte. Conexões, v. 7, n. 2, p. 13-23, 2009.

APA

Brandão, L. (2009) Histórias esquecidas do esporte. Conexões, 7(2),13-23.

VANCOUVER

Brandão L. Histórias esquecidas do esporte. Conexões, 2009; 7(2): 13-23.

Recebido em: 02/06/2009

Aceito para publicação em: jul. 2009 